Alberto L. García-Basteiro, ${ }^{1,2}$, Elisa López-Varela ${ }^{1,2}$, Durval Respeito ${ }^{1}$, Raquel González ${ }^{2}$, Denise Naniche ${ }^{2}$, Ivan Manhiça ${ }^{3}$, Eusebio Macete ${ }^{1}$, Frank Cobelens ${ }^{4}$ and Pedro L. Alonso ${ }^{1,2}$

${ }^{1}$ Manhiça Health Research Center (CISM), Maputo, Mozambique. ${ }^{2}$ ISGlobal, Barcelona Centre for International Health Research (CRESIB), Hospital Clínic - Universitat de Barcelona, Barcelona, Spain. ${ }^{3}$ Ministry of Health, National Tuberculosis Program, Maputo, Mozambique. ${ }^{4}$ Amsterdam Institute for Global Health and Development, Academic Medical Centre, Amsterdam, The Netherlands.

Correspondence: Alberto L. García-Basteiro, Manhiça Health Research Center, Vila da Manhiça, CP 1929 Maputo, Mozambique. E-mail: alberto.garcia-basteiro@manhica.net

Received: Aug 082014 | Accepted after revision: Oct 132014 | First published online: Nov 132014

Conflict of interest: None declared.

Acknowledgements: We thank Sergi Sanz, Elisa de Lazzari (both ISGlobal, CRESIB, Hospital Clínic - Universitat de Barcelona, Barcelona, Spain), Alberto Bila Junior and Elisa Fernández Cooke (both CISM, Maputo, Mozambique) for their support with the statistical analysis, data management and comments on the manuscript.

\title{
References
}

1 World Health Organization. Global Tuberculosis Report 2013. WHO/HTM/TB/2013.11. Geneva, WHO, 2013.

2 García-Basteiro AL, López-Varela E, Manhiça I, et al. Mozambique faces challenges in the fight against tuberculosis. Lancet 2014; 383: 215-216.

3 Getahun H, Gunneberg C, Granich R, et al. HIV infection-associated tuberculosis: the epidemiology and the response. Clin Infect Dis 2010; 50: Suppl. 3, S201-S207.

4 Podlekareva DN, Panteleev AM, Grint D, et al. Short- and long-term mortality and causes of death in HIV/ tuberculosis patients in Europe. Eur Respir J 2014; 43: 166-177.

5 Corbett EL, Bandason T, Cheung YB, et al. Epidemiology of tuberculosis in a high HIV prevalence population provided with enhanced diagnosis of symptomatic disease. PLoS Med 2007; 4: e22.

6 Addis Alene K, Nega A, Wasie Taye B. Incidence and predictors of tuberculosis among adult people living with human immunodeficiency virus at the University of Gondar Referral Hospital, Northwest Ethiopia. BMC Infect Dis 2013; 13: 292.

7 Lawn S, Myer L, Edwards D, et al. Short-term and long-term risk of tuberculosis associated with CD4 cell recovery during antiretroviral therapy in South Africa. AIDS 2013; 23: 1717-1725.

8 Yuen CM, Weyenga HO, Kim A, et al. Comparison of trends in tuberculosis incidence among adults living with HIV and adults without HIV - Kenya, 1998-2012. PLoS One 2014; 9: e99880.

9 Gupta A, Wood R, Kaplan R, et al. Tuberculosis incidence rates during 8 years of follow-up of an antiretroviral treatment cohort in South Africa: comparison with rates in the community. PLoS One 2012; 7: e34156.

10 Sacoor C, Nhacolo A, Nhalungo D, et al. Profile: Manhica Health Research Centre (Manhica HDSS). Int J Epidemiol 2013; 42: 1309-1318.

11 González R, Munguambe K, Aponte J, et al. High HIV prevalence in a southern semi-rural area of Mozambique: a community-based survey. HIV Med 2012; 13: 581-588.

12 Sester M, Giehl C, McNerney R, et al. Challenges and perspectives for improved management of HIV/ Mycobacterium tuberculosis co-infection. Eur Respir J 2010; 36: 1242-1247.

13 Corbett EL, Charalambous S, Moloi VM, et al. Human immunodeficiency virus and the prevalence of undiagnosed tuberculosis in African gold miners. Am J Respir Crit Care Med 2004; 170: 673-679.

14 Glynn JR. Resurgence of tuberculosis and the impact of HIV infection. Br Med Bull 1998; 54: 579-593.

15 Schutz C, Meintjes G, Almajid F, et al. Clinical management of tuberculosis and HIV-1 co-infection. Eur Respir J 2010; 36: 1460-1481.

\section{How is Xpert MTB/RIF being implemented in 22 high tuberculosis burden countries?}

To the Editor:

Accurate and rapid diagnosis is crucial for tuberculosis control by ensuring a timely start to treatment and reducing transmission. In 2012, almost one third of tuberculosis cases were not diagnosed and/or reported to national tuberculosis programmes (NTPs), and $<25 \%$ of estimated incident multidrug-resistant (MDR) cases were diagnosed [1]. Xpert MTB/RIF (Cepheid, Sunnyvale, CA, USA), a nucleic acid amplification test, was recommended in 2010 by the World Health Organization (WHO) for detection of HIV-associated 
pulmonary tuberculosis and rifampicin resistance [2]. In 2013, the test was recommended for detection of paediatric tuberculosis and some forms of extrapulmonary tuberculosis (EPTB), as well as an initial test to replace smear microscopy [3].

Following these recommendations, modules and cartridges have been procured in increasing numbers. As of June 30, 2014, 15846 Xpert modules and 7.5 million cartridges were procured by 104 countries at concessional prices [4], yet the potential market is much larger [5]. Although general policies regarding Xpert in the 22 high-burden countries (HBCs) have been summarised [1] and some experiences from early Xpert implementers are available $[6,7]$, a more comprehensive analysis of NTPs' policies and implementation of Xpert has not been performed.

To assess the current landscape of implementation of Xpert, we designed a standardised questionnaire that was sent to NTPs in 22 HBCs that account for $80 \%$ of tuberculosis cases globally. We contacted NTP managers and representatives with responsibilities relating to Xpert. Questionnaires were completed from January to July 2014, with follow-ups to ensure completion and clarify any ambiguities. Questions covered the following topics: funding sources, instrument placement, access in the private sector, testing algorithms, result reporting and treatment decisions for rifampicin-resistant results. Additionally, to better assess the scale of implementation, we analysed publicly available Xpert procurement data [4].

As shown in table 1 , of the $22 \mathrm{HBCs}, 19$ (86\%) reported an existing national plan or policy pertaining to Xpert. Seven (32\%) of the 22 countries reported the use of domestic funding for Xpert procurement. However, only Brazil and Russia currently fund all Xpert testing with domestic resources, while the majority of HBCs rely on some of the 16 international donor groups identified. As many as six external donors were reported in some countries, suggesting a strong need for in-country coordination.

Until June 2014, of the 7.5 million cartridges procured through public sector pricing, HBCs procured 6.4 million (85\%). Of those, 4.2 million (66\%) of cartridges were procured by South Africa alone, which along with China, India and Brazil, account for $80 \%$ of total HBC procurement. The ratio of smear volumes for initial diagnosis [5] to the number of Xpert cartridges procured during a roughly similar time period was used as an approximate index of Xpert market penetration in the public sector. The ratio in South Africa was 1.6, significantly lower than most other HBCs where approximately 40-70 smears were performed for each Xpert. Evidently, wide-scale implementation of Xpert has only occurred in South Africa, while other HBCs continue to rely heavily on smear microscopy.

While all countries reported deployment of Xpert in the public sector, only five (23\%) reported publicprivate partnerships around Xpert testing, the initiatives to promote the collaboration between private and public health providers in the delivery of tuberculosis care; an additional eight (36\%) use Xpert in other private-sector settings. As Xpert was initially recommended for use at district and subdistrict laboratories [8], eight $(36 \%)$ countries reported the deployment of Xpert at microscopy or peripheral health centres, showing promising progress. 18 (82\%) reported deployment at district and subdistrict levels, and 17 (77\%) reported deployment at reference or centralised laboratories. Although a previous study showed that Xpert implementation is feasible in some primary care facilities [9], the current infrastructure in HBCs might not be adequate for wide-scale coverage [10].

With respect to testing algorithms, only South Africa, Brazil and Russia recommend Xpert for all people suspected of having tuberculosis. Additionally, Brazil reported plans to replace smear microscopy with Xpert in 92 cities across the country. Although all HBCs recommend Xpert as an initial test for drug-resistant tuberculosis (DR-TB), eligibility criteria vary among them. Four countries recommend Xpert only for patients with suspected drug resistance, although in Pakistan and Bangladesh, Xpert is also being used for general tuberculosis case finding at selected sites [7]. The remaining 19 HBCs recommend Xpert among HIV-infected patients, although in Thailand and Uganda, Xpert is recommended only after negative smear results, against WHO recommendations. However, given the limited number of cartridges procured outside South Africa, actual application of these algorithms is likely to be limited. Testing strategies focusing on the detection of drug resistance among retreatment cases only identify a fraction of total new MDR cases in most countries and will limit the ability to scale-up DR-TB treatment programmes. Ultimately, countries have to work towards universal drug susceptibility testing (DST) as outlined in the Global Plan and Post-2015 Global TB Strategy [11, 12], but this will require greater resources.

While updated policy guidance on Xpert for the diagnosis of paediatric tuberculosis and EPTB was only issued in October 2013, 14 (59.1\%) countries already reported recommending Xpert in children suspected of having tuberculosis. The use of Xpert for EPTB diagnosis was recommended in four (18\%) countries.

WHO developed new recording and reporting recommendations in 2013 largely in response to the introduction of new molecular tests [13]. 14 (64\%) countries recommended recording Xpert-positive results as bacteriologically positive, while three (14\%) reported having no standards for reporting at this 
TABLE 1 Policy and implementation data on Xpert MTB/RIF from 22 high tuberculosis (TB) burden countries

\begin{tabular}{|c|c|c|c|c|c|c|c|c|c|c|c|}
\hline \multirow{2}{*}{$\begin{array}{l}\text { Country (WHO } \\
\text { classification) }\end{array}$} & \multirow{2}{*}{$\begin{array}{l}\text { Estimated } \\
\text { HIV }^{+} \text {TB } \\
\text { cases }^{\#} \mathrm{n}\end{array}$} & \multirow{2}{*}{$\begin{array}{l}\text { Estimated } \\
\text { MDR-TB } \\
\text { among } \\
\text { notified TB } \\
\text { cases }^{\#} \mathrm{n}\end{array}$} & \multirow{2}{*}{$\begin{array}{l}\text { Total MDR } \\
\text { cases that } \\
\text { are new TB } \\
\text { cases }^{\#, \pi} \%\end{array}$} & \multirow{2}{*}{$\begin{array}{l}\text { Xpert } \\
\text { policy }\end{array}$} & \multirow{2}{*}{$\begin{array}{l}\text { Cartridges } \\
\text { procured }^{\S} n\end{array}$} & \multirow{2}{*}{$\begin{array}{c}\text { Smear/ } \\
\text { Xpert } \\
\text { cartridge } \\
\text { ratiof }^{f}\end{array}$} & \multirow{2}{*}{$\begin{array}{c}\text { Modules } \\
\text { procured }^{\S} \\
n\end{array}$} & \multirow{2}{*}{$\begin{array}{c}\text { Availability } \\
\text { in private } \\
\text { sector }\end{array}$} & \multirow[t]{2}{*}{ Algorithm } & \multicolumn{2}{|c|}{ SLT initiation } \\
\hline & & & & & & & & & & $\begin{array}{l}\text { Patients with } \\
\text { high risk of DR }\end{array}$ & $\begin{array}{l}\text { Patients with } \\
\text { low risk of DR }\end{array}$ \\
\hline Afghanistan & 310 & 1150 & 65 & $\mathrm{~N}$ & $570(460)$ & 37.0 & 6 & $\mathrm{~N}$ & DR & Treat w/DST & Treat w/ DST \\
\hline $\begin{array}{l}\text { Bangladesh } \\
\text { (HDR) }\end{array}$ & 240 & 4200 & 45 & Y & 114910 (96 300) & 15.0 & 376 & Y w/PPM & $\mathrm{DR}$ & Treat no DST & Treat w/ DST \\
\hline $\begin{array}{l}\text { Brazil } \\
\text { (HTH) }\end{array}$ & 16000 & 1710 & 50 & Y & 290930 (256 670) & 6.2 & 716 & Y w/o PPM & $\begin{array}{c}\text { All } \\
\text { EPTB } \\
\text { Children }\end{array}$ & \multicolumn{2}{|c|}{ Under revision } \\
\hline $\begin{array}{l}\text { Cambodia } \\
\text { (HTH) }\end{array}$ & 2700 & 386 & 85 & Y & 57640 (20 690) & 21.1 & 96 & $N$ & $\begin{array}{c}\mathrm{DR} \\
\mathrm{HIV}^{+}\end{array}$ & Treat w/DST & Wait \\
\hline $\begin{array}{l}\text { China } \\
\text { (HDR, HTH) }\end{array}$ & 7300 & 60000 & 82 & Y & $240000(227560)$ & 74.3 & 3812 & Y w/o PPM & $\mathrm{DR}$ & Treat no DST & Wait \\
\hline $\begin{array}{l}\text { DR Congo } \\
\text { (HDR, HTH) }\end{array}$ & 16000 & 2860 & 73 & Y & $67740(24780)$ & 31.2 & 110 & $\mathrm{~N}$ & $\begin{array}{c}\mathrm{DR} \\
\mathrm{HIV}^{+}\end{array}$ & Treat w/DST & Treat w/DST \\
\hline $\begin{array}{l}\text { Ethiopia } \\
\text { (HDR, HTH) }\end{array}$ & 23000 & 2080 & 77 & Y & 37040 (12 680) & 378.5 & 104 & Y w/o PPM & $\begin{array}{c}\text { DR } \\
\text { HIV } \\
\text { Children }\end{array}$ & Treat no DST & Treat w/o DST \\
\hline $\begin{array}{l}\text { India } \\
\text { (HDR, HTH) }\end{array}$ & 130000 & 64000 & 33 & Y & 379200 (232 150) & 71.5 & 598 & Y w/PPM & $\begin{array}{c}\text { DR } \\
\text { HIV }^{+} \\
\text {Children }\end{array}$ & Treat w/DST & Wait \\
\hline $\begin{array}{l}\text { Indonesia } \\
\text { (HDR, HTH) }\end{array}$ & 7500 & 6800 & 85 & Y & 52950 (41 250) & 39.3 & 284 & Y w/PPM & $\begin{array}{c}\mathrm{DR} \\
\mathrm{HIV}^{+}\end{array}$ & Treat w/DST & Wait \\
\hline $\begin{array}{l}\text { Kenya } \\
\text { (HTH) }\end{array}$ & 45000 & 2780 & 65 & Y & 147950 (81 010) & 47.6 & 370 & Y w/PPM & $\begin{array}{c}\text { DR } \\
\text { HIV }^{+} \\
\text {Children }\end{array}$ & Treat w/DST & Wait \\
\hline $\begin{array}{l}\text { Mozambique } \\
\text { (HTH) }\end{array}$ & 83000 & 1940 & 72 & Y & 76020 (31 700) & 6.2 & 108 & $N$ & $\begin{array}{c}\text { DR } \\
\text { HIV }^{+} \\
\text {Children }\end{array}$ & Treat w/DST & Treat w/DST \\
\hline $\begin{array}{l}\text { Myanmar } \\
\text { (HDR, HTH) }\end{array}$ & 19000 & 6100 & 80 & Y & $72520(40100)$ & 23.2 & 164 & $N$ & $\begin{array}{c}\text { DR } \\
\text { HIV }^{+} \\
\text {Children }\end{array}$ & Wait & Wait \\
\hline $\begin{array}{l}\text { Nigeria } \\
\text { (HDR, HTH) }\end{array}$ & 46000 & 3600 & 69 & Y & 76840 (38 080) & 27.8 & 400 & Y w/PPM & $\begin{array}{c}\text { DR } \\
\text { HIV }^{+} \\
\text {EPTB }\end{array}$ & Wait & Wait \\
\hline $\begin{array}{l}\text { Pakistan } \\
\text { (HDR) }\end{array}$ & 3800 & 11400 & 68 & Y & 98200 (45 860) & 31.0 & 294 & Y w/PPM & $\begin{array}{l}\text { DR } \\
\text { HIV }^{+} \\
\text {EPTB }\end{array}$ & Treat w/DST & $\begin{array}{l}\text { Wait for 2nd } \\
\text { Xpert }\end{array}$ \\
\hline $\begin{array}{l}\text { Philippines } \\
\text { (HDR) }\end{array}$ & 460 & 15300 & 55 & Y & 71780 (34 350) & 41.9 & 404 & Y w/PPM & $\begin{array}{c}\text { DR } \\
\text { HIV }^{+} \\
\text {EPTB } \\
\text { Children }\end{array}$ & Wait & Wait \\
\hline $\begin{array}{l}\text { Russia (HDR, } \\
\text { HTH) }\end{array}$ & 9300 & 45000 & 44 & $\mathrm{~N}$ & 15490 (2 950) & 2386.4 & 58 & $\mathrm{~N}$ & All & Treat w/DST & Treat w/DST \\
\hline & 330000 & 8100 & 43 & Y & & 1.6 & 4132 & Y w/o PPM & & Treat w/DST & Wait \\
\hline
\end{tabular}




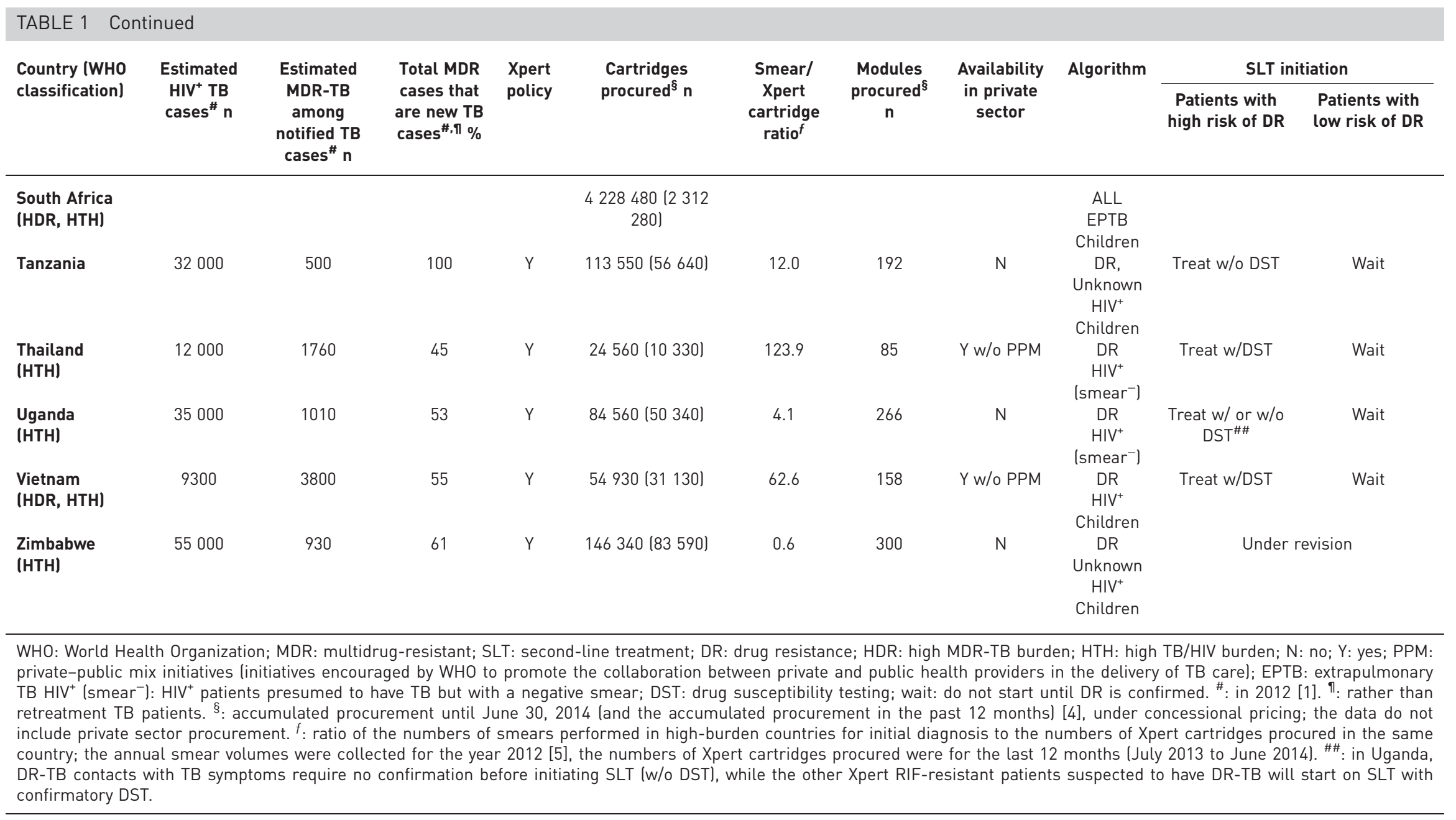


time. These findings demonstrate progress after some early implementers documented challenges around unclear and inconsistent reporting [7].

Initial WHO guidance for treatment decisions for patients with rifampicin resistance but not at risk for DR-TB recommended follow-up DST using another method, citing poor positive predictive values for Xpert [2]. Recent evidence suggests that using phenotypic DST as the reference standard misses some rifampicin-resistant cases [14]. Currently, WHO recommends that a rifampicin-resistant Xpert result for persons suspected of having DR-TB is sufficient to initiate second-line treatment (SLT) [3]. Most countries initiate SLT for those with risk factors for drug resistance (without confirmation or while waiting for confirmation of Xpert results), while three (14\%) require confirmatory DST prior to SLT initiation. For patients at low risk of drug resistance, 13 (59\%) countries require confirmatory DST before initiating SLT. A number of countries reported that current guidelines are under review and likely to change as more evidence becomes available.

Overall, we found the uptake of WHO guidelines on Xpert has been relatively quick compared with other guidelines on new tuberculosis diagnostics, such as light-emitting diode microscopy or same-day smear diagnosis. However, previous studies [7] suggest the implementation of Xpert in the field may deviate from stated national policy, and we found current Xpert testing is mainly donor-funded, mostly limited to district or reference laboratories, and primarily used in patients suspected of having DR-TB, and to a lesser extent among persons suspected of HIV-associated tuberculosis. Models suggest that more restrictive implementation strategies might limit the impact of Xpert [15]. Therefore, we hope these results will serve to raise awareness about the need for more ambitious testing algorithms (e.g. universal DST) and implementation for greater impact, acknowledging this will only be possible with much greater investments in improved tuberculosis diagnosis and care from both donors and domestic funding.

@ERSpublications

Xpert MTB/RIF implementation is mainly donor-funded, focused on DST and is not widely used outside South Africa http://ow.ly/CK4NS

Zhi Zhen Qin ${ }^{1}$, Madhukar Pai ${ }^{1}$, Wayne Van Gemert ${ }^{2}$, Suvanand Sahu ${ }^{3}$, Marzieh Ghiasi ${ }^{1}$ and Jacob Creswell ${ }^{3}$

${ }^{1}$ McGill International TB Centre, and Dept of Epidemiology and Biostatistics, McGill University, Montreal, Canada.

${ }^{2}$ Global TB Progamme, World Health Organization, Geneva, Switzerland. ${ }^{3}$ Stop TB Partnership, Geneva, Switzerland.

Correspondence: Jacob Creswell, Stop TB Partnership Secretariat, 20, Avenue Appia, Geneva, Switzerland.

E-mail: creswellj@stoptb.who.int

Received: Aug 122014 | Accepted after revision: Oct 062014 | First published online: Oct 302014

Conflict of interest: Disclosures can be found alongside the online version of this article at erj.ersjournals.com

Acknowledgements: We are grateful to all NTP staff and respondents who completed the surveys and answered our follow-up questions. We are also grateful to Claudia Denkinger (Foundation for Innovative New Diagnostics, Geneva, Switzerland), Sandra Kik (KNCV Tuberculosis Foundation, The Hague, The Netherlands) and Pamela Chedore (independent laboratory consultant, Toronto, Canada) for useful input on the survey design.

\section{References}

1 World Health Organization. Global tuberculosis report 2013. Geneva, WHO, 2013.

2 World Health Organization. Policy statement: automated real-time nucleic acid amplification technology for rapid and simultaneous detection of tuberculosis and rifampicin resistance: Xpert MTB/RIF system. Geneva, WHO, 2011.

3 World Health Organization. Automated real-time nucleic acid amplification technology for rapid and simultaneous detection of tuberculosis and rifampicin resistance: Xpert MTB/RIF assay for the diagnosis of pulmonary and extrapulmonary TB in adults and children. Policy update. Geneva, WHO, 2013.

4 World Health Organization. WHO monitoring of Xpert MTB/RIF roll-out 2014. www.stoptb.org/wg/gli/assets/ documents/map/1/atlas.html Date last accessed: July 21, 2014.

5 Kik SV, Denkinger CM, Chedore P, et al. Replacing smear microscopy for the diagnosis of tuberculosis: what is the market potential?. Eur Respir J 2014; 43: 1793-1796.

6 World Health Organization . 6th Global Laboratory Initiative (GLI) Partners Meeting 2014. www.stoptb.org/wg/ gli/assets/html/6th\%20GLI\%20meeting\%20AGENDA-for\%20WEBSITE.htm.

7 Creswell J, Codlin AJ, Andre E, et al. Results from early programmatic implementation of Xpert MTB/RIF testing in nine countries. BMC Infect Dis 2014; 14: 2 .

8 Weyer K, Mirzayev F, Migliori GB, et al. Rapid molecular TB diagnosis: evidence, policy making and global implementation of Xpert MTB/RIF. Eur Respir J 2013; 42: 252-271.

9 Theron G, Zijenah L, Chanda D, et al. Feasibility, accuracy, and clinical effect of point-of-care Xpert MTB/RIF testing for tuberculosis in primary-care settings in Africa: a multicentre, randomised, controlled trial. Lancet 2014; 383: 424-35.

10 Denkinger CM, Nicolau I, Ramsay A, et al. Are peripheral microscopy centres ready for next generation molecular tuberculosis diagnostics?. Eur Respir J 2013; 42: 544-547.

11 Stop TB Partnership. The global plan to stop TB 2011-2015: transforming the fight towards elimination of tuberculosis. Geneva, WHO, 2010. 
12 World Health Organization. Sixty-Seventh World Health Assembly. A67/11. Draft global strategy and targets for tuberculosis prevention, care and control after 2015. Geneva, WHO, 2014.

13 World Health Organization. Definitions and reporting framework for tuberculosis - 2013 revision. Geneva, WHO, 2013.

14 Van Deun A, Maug AK, Bola V, et al. Rifampicin drug resistance tests for tuberculosis: challenging the gold standard. J Clin Microbiol 2013; 51: 2633-2640.

15 Salje H, Andrews JR, Deo S, et al. The importance of implementation strategy in scaling up Xpert MTB/RIF for diagnosis of tuberculosis in the Indian health-care system: a transmission model. PLoS Med 2014; 11: e1001674.

\section{A mutation associated with clofazimine and bedaquiline cross-resistance in MDR-TB following bedaquiline treatment}

To the Editor:

The world-wide increase in the incidence of multidrug-resistant tuberculosis (MDR-TB) and extensively drug-resistant tuberculosis (XDR-TB) poses a major clinical challenge. The treatment outcome of MDR-TB and XDR-TB patients is often poor and unsuccessful in the absence of an optimal number of active drugs [1]. Novel antituberculous compounds are urgently required and only very few, such as bedaquiline, have recently been approved for tuberculosis treatment [2]. In a recent phase $2 \mathrm{~b}$ clinical trial that was based on a 160 newly diagnosed MDR-TB patients, the addition of bedaquiline to a preferred background regimen for 24 weeks resulted in faster culture conversion and significantly more culture conversion at 120 weeks compared with the control group. However, there were more deaths in the bedaquiline than in the placebo group and half of these patients died due to tuberculosis. So far, it is unclear whether the death of any of these patients may have been associated with diminished susceptibility to bedaquiline [3].

Our study indicates that emergence of drug resistance to bedaquiline is already an ongoing threat, as we provide in vivo evidence of acquired resistance due to a mutation in an efflux pump-related gene, and its association with clofazimine and bedaquiline cross resistance in an Mycobacterium tuberculosis isolate from a patient with MDR-TB. In January 2011, a Tibetan refugee hospitalised with bilateral cavernous chest radiograph abnormality was diagnosed with MDR-TB at the Swiss Reference Center for Mycobacteria, Zurich, Switzerland. The M. tuberculosis isolate from the patient showed resistance to isoniazid, rifampicin, pyrazinamide, ethionamide, linezolid, moxifloxacin and streptomycin by quantitative drug susceptibility testing (DST) in the BACTEC MGIT 960 system (Becton-Dickinson Inc., East Rutherford, NJ, USA) (table 1) [4]. In line with the DST results, a combined and directly observed antituberculous therapy was initiated with cycloserine, capreomycin, para-aminosalicylic acid (PAS) and ethambutol. Published evidence indicates that treatment outcome of patients with MDR-TB whose isolates show resistance either to pyrazinamide or fluoroquinolones is poor in the absence of an adequate number of active drugs $[5,6]$. In order to strengthen the efficacy of therapy with the less potent second-line drugs, the patient received bedaquiline on a compassionate basis between September 2011 and February 2012. Culture conversion was confirmed at the end of October 2011. The patient remained culture negative and therapy was terminated in March 2013.

In August 2013, the patient was re-admitted with fever, cough and acid-fast bacillus-positive sputum microscopy. Therapy was re-initiated with cycloserine, capreomycin, PAS, ethambutol, clofazimine and inhaled amikacin. Re-application for bedaquiline treatment was rejected by the manufacturer on the basis that the patient had already received treatment on a compassionate basis for 6 months. DST of the relapse isolate in 2013 confirmed the previous resistance pattern but, to our surprise, revealed additional resistance to clofazimine. The 2011 isolate was susceptible to clofazimine (table 1). Most notably, the patient never received clofazimine. Genotyping using 24-locus mycobacterial interspersed repetitive unit variable number tandem repeats did not identify differences between the post-relapse and the previous isolates from 2011, indicating a common clonal origin of these isolates [7]. Recently, HARTKOORN et al. [8] described a mechanism of cross-resistance between clofazimine and bedaquiline in in vitro-selected 